\title{
ANALYSIS OF THE EFFECTS OF RESIDUAL STRAINS AND DEFECTS ON SKIN/STIFFENER DEBONDING USING DECOHESION ELEMENTS
}

\author{
Carlos G. Dávila \\ Aerospace Engineer, Analytical and Computational Methods Branch, Senior Member, AIAA. \\ NASA Langley Research Center, Hampton, VA 23681 \\ Pedro P. Camanho \\ Assistant Professor, University of Porto \\ Porto, Portugal
}

\begin{abstract}
$\underline{\text { Abstract }}$
Delamination is one of the predominant forms of failure in laminated composites especially when there is no reinforcement in the thickness direction. To develop composite structures that are more damage tolerant, it is necessary to understand how delamination develops and how it can affect the residual performance. A number of factors such as residual thermal strains, matrix curing shrinkage, and manufacturing defects affect how damage will grow in a composite structure. It is important to develop analysis methods that are computationally efficient that can account for all such factors. The objective of the current work is to apply a newly developed decohesion element to investigate the debond strength of skin/stiffener composite specimens. The process of initiation of delaminations and the propagation of delamination fronts is investigated. The numerical predictions are compared with published experimental results.
\end{abstract}

\section{INTRODUCTION}

Interlaminar cracks (delaminations), as a result of impact or a manufacturing defect, can cause a significant reduction in the compressive load-carrying capacity of a composite structure. The stress gradients that occur near geometric discontinuities such as ply drop-offs, stiffener terminations and flanges, promote delamination initiation, trigger intraply damage mechanisms, and cause a significant loss of structural integrity. The study of delamination mechanics may be divided into the study of delamination initiation and the analysis of delamination propagation. Delamination initiation analyses are usually based on stresses and use criteria such as the quadratic interaction of the interlaminar stresses in conjunction with a characteristic distance. ${ }^{1,2}$ The characteristic distance is an averaging length that is a function of geometry and material properties, so its determination always requires extensive testing.

Most analyses of delamination growth apply a fracture mechanics approach and evaluate energy release rates, $G$, for self-similar delamination growth. The $G$ values are usually evaluated using the virtual crack closure technique (VCCT) proposed by Rybicki and Kanninen ${ }^{3}$. The approach is computationally effective since the energy release rates can be obtained from only one analysis.

In the present paper, an approach is proposed that is well suited to progressive failure analyses where delaminations are present. The approach consists of placing interfacial decohesion elements between composite layers. The proposed constitutive equations for the interface are phenomenological mechanical relations between the tractions and interfacial separations. With increasing interfacial separation, the tractions across the interface reach a maximum, decrease, and vanish when complete decohesion occurs. The work of normal and tangential separation can be related to the critical values of energy release rates $^{4}$.

In order to predict the initiation and growth of delamination, an 8-node decohesion element is developed and implemented in the ABAQUS finite element $\operatorname{code}^{5}$. The decohesion element is used to model the interface between sublaminates or between two bonded components. The material response built into the element represents damage using a cohesive zone ahead of the crack tip to predict delamination growth. 


\section{ELEMENT FORMULATION}

\section{$\underline{2.1 \text { Kinematics }}$}

A zero-thickness decohesion element with 8-nodes is proposed to simulate the resin-rich layer connecting two laminae of a composite laminate. The constitutive equation of zero-thickness decohesion elements is established in terms of relative displacements and tractions across the interface. The vector defining the relative displacement in global coordinates is:

$$
\Delta_{i}=u_{i}^{+}-u_{i}^{-}=N_{k} u_{k i}^{+}-N_{k} u_{k i}^{-}=\bar{N}_{k} u_{k i}
$$

where $N_{k}$ are standard Lagrangian shape functions, and $u_{i}^{+}$and $u_{i}^{-}$are the components of the displacements of the top and bottom surfaces, respectively.

For a general element shape and alignment, the normal and tangential relative displacements $\delta_{s}$ must be determined in local coordinates. The transformation between the global and the local coordinate fame is accomplished using the rotation tensor $\theta_{s i}$ defined in Ref. 6:

$$
\delta_{s}=\theta_{s i} \Delta_{i}=\theta_{s i} \bar{N}_{k} u_{k i}=B_{s i k} u_{k i}
$$

\subsection{Constitutive Equation}

The need for an appropriate constitutive equation in the formulation of the decohesion element is fundamental for an accurate simulation of the interlaminar cracking process. A constitutive equation is used to relate the traction, $\tau$, to the relative displacement, $\delta$, at the interface. Some softening models that have been proposed are shown in Figure 1. One characteristic of all softening models is that the cohesive zone can still transfer load after the onset of damage ( $\delta^{0}$ in Figure 1). For pure mode I, II or III loading, after the interfacial normal or shear tractions attain their respective interlaminar tensile or shear strengths, the stiffnesses are gradually reduced to zero. The area under the traction-relative displacement curves is the respective (mode I, II or III) fracture energy. Using the definition of the $J$ integral $^{7}$, it can be shown that for small cohesive zones ${ }^{4}$ :

$$
\int_{0}^{\delta^{f}} \tau(\delta) d \delta=G_{C}
$$

where $G_{C}$ is the critical energy release rate for a particular mode, and $\delta^{f}$ is the corresponding relative displacement at failure $\left(\delta^{f}=\delta_{p p}, \delta_{\text {pro }}, \delta_{\text {lin }}, \delta_{\mathrm{Ne}}\right.$, or $\delta_{\text {reg }}$ in Figure 1).

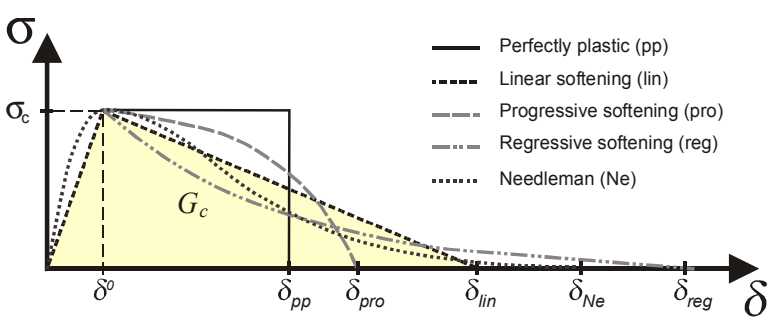

Figure 1. Softening constitutive models.

\subsection{Mixed-Mode Delamination Criterion}

In structural applications of composites, delamination growth is likely to occur under mixedmode loading. Therefore, a general formulation for decohesion elements must deal with mixed-mode delamination growth problems.

Under pure mode I, II or III loading, the onset of damage at the interface can be determined simply by comparing the tractions with their respective allowable. Under mixed-mode loading, however, damage onset may occur before any of the stress components involved reach their respective allowable. The mixed-mode criterion proposed assumes that damage initiation can be predicted using the quadratic failure criterion:

$$
\sqrt{\left(\frac{\left\langle\tau_{3}\right\rangle}{T}\right)^{2}+\left(\frac{\tau_{2}}{S}\right)^{2}+\left(\frac{\tau_{1}}{S}\right)^{2}}=1
$$

where $\tau_{3}$ is the normal traction, and $\tau_{2}$ and $\tau_{1}$ are the transverse tractions. $T$ and $S$ are the nominal normal tensile and shear strengths, respectively. The operator $<x>$ is defined as $x$ if $x>0$, and 0 otherwise.

The delamination mechanisms in mode II and mode III are assumed to be the same. Therefore, mode III can be combined with mode II by using a total tangential displacement $\delta_{\text {shear }}$ defined as the norm of the 
two orthogonal tangential relative displacements $\delta_{1}$ and $\delta_{2}$.

$$
\delta_{\text {shear }}=\sqrt{\delta_{1}^{2}+\delta_{2}^{2}}
$$

The total mixed-mode relative displacement $\delta_{m}$ is defined as:

$$
\delta_{m}=\sqrt{\left\langle\delta_{3}\right\rangle^{2}+\delta_{\text {shear }}^{2}}
$$

where $\delta_{3}$ is the relative opening (mode I) displacement. Using the same penalty stiffness $K_{P}$ in modes I and II, the tractions before the onset of damage are:

$$
\tau_{i}=K_{P} \delta_{i}, i=1,2,3
$$

The single-mode failure initiation displacements are then:

$$
\begin{aligned}
& \delta_{2}^{0}=\delta_{1}^{0}=\delta_{\text {shear }}^{0}=\frac{S}{K_{P}} \\
& \delta_{3}^{0}=\frac{T}{K_{P}}
\end{aligned}
$$

If the relative opening displacement $\delta_{3}$ is not zero, the mode mixity can be expressed by:

$$
\beta=\frac{\delta_{\text {shear }}}{\delta_{3}}
$$

The mixed-mode damage initiation displacement is obtained by substituting Eqs. 5-9 into 4, which gives:

$$
\delta_{m}^{0}=\delta_{1}^{0} \delta_{3}^{0} \sqrt{\frac{1+\beta^{2}}{\left(\delta_{1}^{0}\right)^{2}+\left(\beta \delta_{3}^{0}\right)^{2}}}
$$

The criteria used to predict delamination propagation under mixed-mode loading conditions are generally established in terms of the energy release rates and fracture toughness. The most widely used criteria to predict the interaction of the energy release rates in mixed-mode is the power law given by the expression:

$$
\left(\frac{G_{I}}{G_{I c}}\right)^{\alpha}+\left(\frac{G_{I I}}{G_{I I c}}\right)^{\alpha}=1
$$

The exponent $\alpha$ in the power law is usually selected to be either 1 or 2 , in which case the criterion is a twoparameter interaction law with parameters $G_{I C}$ and $G_{I I C}$. A recently proposed criterion, the B-K criterion ${ }^{8}$, is established in terms of the single-mode fracture toughnesses $G_{I C}$ and $G_{I I C}$ and a parameter $\eta$ :

$$
G_{T}=G_{I c}+\left(G_{I I c}-G_{I c}\right)\left(\frac{G_{I I}}{G_{T}}\right)^{\eta}
$$

Reeder ${ }^{9}$ applied the B-K criterion to mixed-mode test results of AS4/3501-6 and obtained a best fit using $\eta=1.45$, which is shown in Figure 2 .

The linear $(\alpha=1)$ and quadratic $(\alpha=2)$ criteria, which are also shown in Figure 2, do not correlate well with the experimental results for this material. Therefore, in order to accurately account for the variation of fracture toughness as a function of mode ratio, the B-K criterion is implemented here.

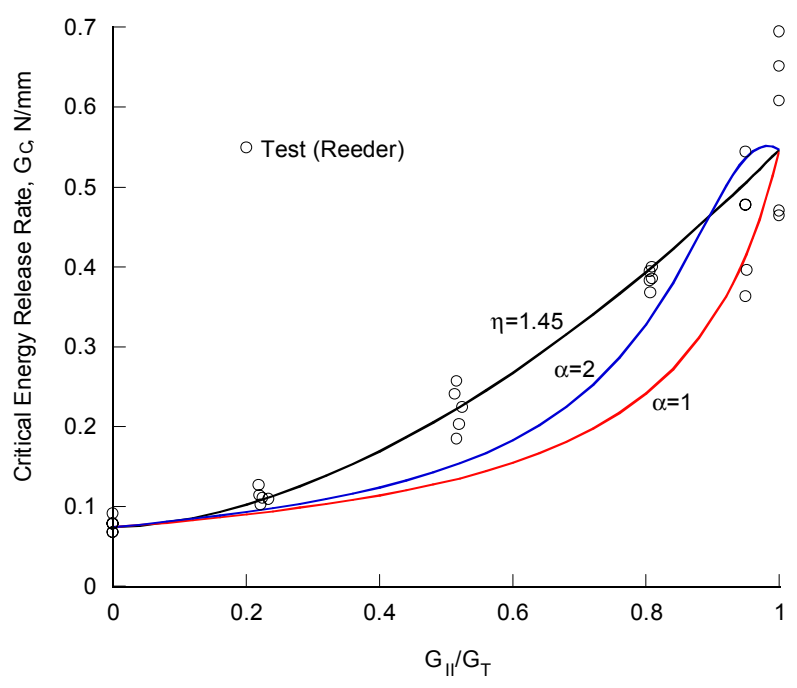

Figure 2. $G_{C}$ versus $G_{I I} / G_{T}$ mode ratio for AS4/3501-6.

For the bilinear traction-relative displacement softening law assumed here, the critical energy release rates in mode I and mode II are:

$$
G_{I c}=\frac{T \delta_{3}^{f}}{2} \quad ; \quad G_{I I c}=\frac{S \delta_{2}^{f}}{2}
$$

where $\delta_{3}^{f}$ and $\delta_{2}^{f}$ are the ultimate opening and tangential displacements, respectively. The mode I and 
mode II energies released at failure are computed from:

$$
\begin{aligned}
G_{I} & =\int_{0}^{\delta_{m}^{3 f}} \tau_{3} d \delta_{3} \\
G_{I I} & =\int_{0}^{\delta_{m}^{2 f}} \tau_{2} d \delta_{2}
\end{aligned}
$$

where $\delta_{m}^{3 f}$ and $\delta_{m}^{2 f}$ are the mode I and mode II relative displacements at failure under mixed-mode loading. Using the definition of the mixed-mode relative displacement $\delta_{m}$ in Eq. 6 and the mode mixity ratio $\beta$ given by Eq. 9, one can solve for the ultimate relative displacement $\delta_{m}^{f}$. For the B-K criterion in Eq.

12 , the ultimate relative displacement is then:

$$
\delta_{m}^{f}=\frac{2}{K_{p} \delta_{m}^{0}}\left[G_{I C}+\left(G_{I I C}-G_{I C}\right)\left(\frac{\beta^{2}}{1+\beta^{2}}\right)^{\eta}\right]
$$

Having defined the relative displacement corresponding to damage onset, $\delta_{m}^{0}$, and total decohesion, $\delta_{m}^{f}$, the constitutive equation can be defined as:

$$
\tau_{s}=D_{s r} \delta_{r}
$$

The constitutive operator $D_{s r}$ is defined in Ref 6 as:

$$
D_{s r}=\left\{\begin{array}{lc}
\bar{\delta}_{s r} K_{p}, & \delta_{m}^{\max } \leq \delta_{m}^{0} \\
\bar{\delta}_{s r} K_{p}\left[(1-d) K_{p}+d K_{p} \bar{\delta}_{s 3} \frac{\left\langle-\delta_{3}\right\rangle}{-\delta_{3}}\right], & \delta_{m}^{0}<\delta_{m}^{\max }<\delta_{m}^{f} \\
\bar{\delta}_{s 3} \bar{\delta}_{3 r} \frac{\left\langle-\delta_{3}\right\rangle}{-\delta_{3}} K_{p}, & \delta_{m}^{\max } \geq \delta_{m}^{f}
\end{array}\right.
$$

where $\bar{\delta}_{s r}$ is the Kronecker delta, $\delta_{m}^{\max }$ is the maximum value (over time) of the relative displacement, and

$$
d=\frac{\delta_{m}^{f}\left(\delta_{m}^{\max }-\delta_{m}^{0}\right)}{\delta_{m}^{\max }\left(\delta_{m}^{f}-\delta_{m}^{0}\right)}, \quad d \in[0,1]
$$

The element stiffness matrix is obtained using the Principle of Virtual Work:

$$
K_{k i z v} u_{z v}=f_{k i}
$$

with:

$$
K_{k i z v}=\int_{A} D_{s r} B_{r z v}\left(\frac{\partial B_{s p y}}{\partial u_{k i}} u_{y p}+B_{s i k}\right) d A
$$

The irreversibility of the damage process is taken into account by using the maximum value of the relative displacement, $\delta_{m}^{\max }$, rather than the current value.

The integration is performed numerically using a Newton-Cotes integration, which has been shown to perform better than Gaussian integration in problems involving strain softening. ${ }^{4}$ The element proposed is implemented in $\mathrm{ABAQUS}^{5}$ as a user-defined element.

\section{ELEMENT VALIDATION}

Before simulating structural components, the proposed approach is validated by comparing the predictions with experimental data obtained for double-cantilever beam (DCB-mode I loading), endnotched flexure (ENF-mode II loading) and mixedmode bending (MMB-mixed-mode I and II) tests in unidirectional AS4/PEEK carbon-fiber reinforced composite. The geometry of the specimens and the material properties are presented in Ref. 6. The experimental tests were performed at different $G_{I I} /\left(G_{I}+G_{I I}\right)$ ratios, ranging from pure mode I loading to pure mode II loading.

The initial size of the delamination is simulated by placing open decohesion elements along the length corresponding to the initial delamination of each specimen. These elements are capable of dealing with the contact conditions occurring for mode II or mixedmode I and II loading, therefore avoiding interpenetration of the delamination faces. The numerical predictions and the experimental data for the test cases simulated are shown in Fig. 3.

It can be concluded that a good agreement between the numerical predictions and the experimental results is obtained. The largest difference (8.3\%) corresponds to the case of an MMB test specimen with $G_{I I} /\left(G_{I}+G_{I I}\right)$ $=20 \%$. 


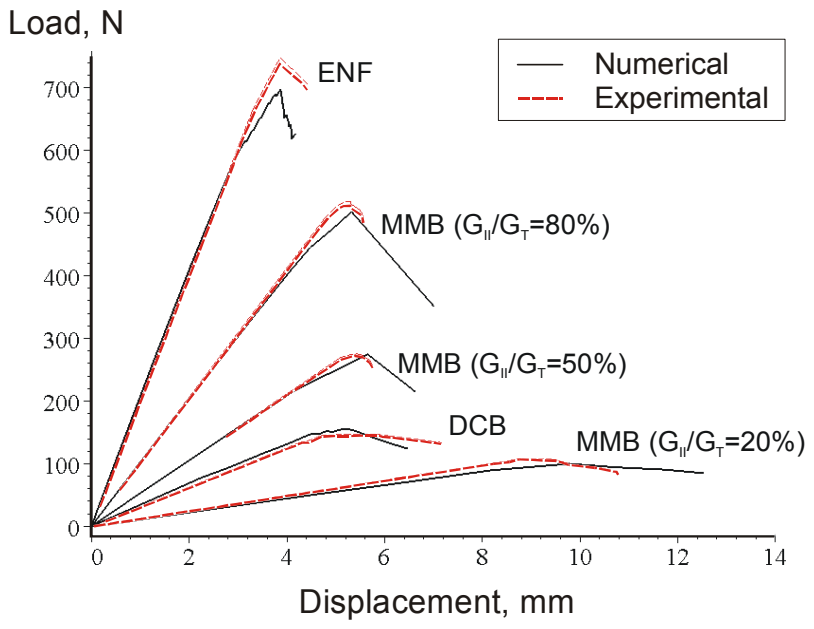

Figure 3. Experimental and predicted loaddisplacement relations.

\section{ANALYSIS OF SKIN-STIFFENER DEBONDING}

Most composite components in aerospace structures are made of panels with co-cured or adhesively bonded frames and stiffeners. Testing of stiffened panels has shown that bond failure at the tip of the stiffener flange is a common failure mode. Comparatively simple specimens consisting of a stringer flange bonded onto a skin have been developed by Krueger et al. to study skin/stiffener debonding ${ }^{10}$. The configuration of the specimens studied in Ref. 10 is shown in Figure 4. The specimens are $203 \mathrm{~mm}$-long, $25.4 \mathrm{~mm}$-wide. Both skin and flange were made from IM6/3501-6 graphite/epoxy prepreg tape with a nominal ply thickness of $0.188 \mathrm{~mm}$. The skin lay-up consisting of 14 plies was $[0 / 45 / 90 /-45 / 45 /-45 / 0]_{\mathrm{s}}$ and the flange lay-up consisting of 10 plies was [45/90/-45/0/90]s.

The properties of the unidirectional graphite/epoxy and the properties of the interface reported in Ref. 10 are shown in Tables 1 and 2, respectively.

The relative mode I and mode II displacements for damage onset are $\delta_{3}^{0}=61 \times 10^{-6} \mathrm{~mm}$ and $\delta_{2}^{0}=68 \times 10^{-6} \mathrm{~mm}$, respectively. The corresponding ultimate relative displacements are $\delta_{3}^{f}=2.46 \times 10^{-3} \mathrm{~mm}$ and $\delta_{2}^{f}=17.5 \times 10^{-3} \mathrm{~mm}$. The parameter $\eta=1.45$ for the $\mathrm{B}-\mathrm{K}$ criterion is taken from test data for AS4/3501-6.
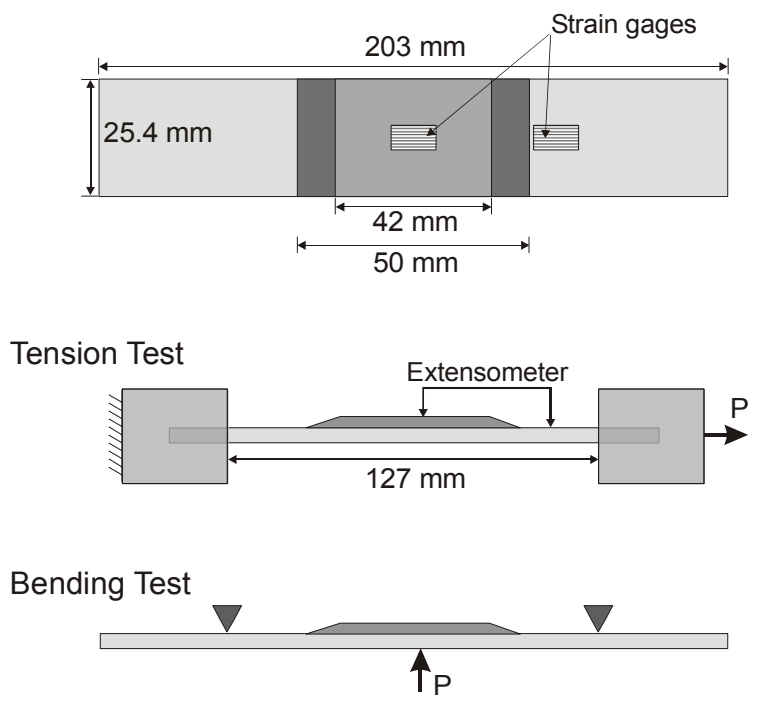

Figure 4. Skin-stiffener specimen configuration (not to scale).

Table 1. Material Properties of IM6/3501-6 Unidirectional Graphite/Epoxy ${ }^{10}$

\begin{tabular}{cccccc}
\hline \hline $\begin{array}{c}\mathrm{E}_{11} \\
(\mathrm{GPa})\end{array}$ & $\begin{array}{c}\mathrm{E}_{22}=\mathrm{E}_{33} \\
(\mathrm{GPa})\end{array}$ & $v_{12}=v_{13}$ & $v_{23}$ & $\begin{array}{c}\mathrm{G}_{12}=\mathrm{G}_{13} \\
(\mathrm{GPa})\end{array}$ & $\begin{array}{c}\mathrm{G}_{23} \\
(\mathrm{GPa})\end{array}$ \\
\hline 144.7 & 9.65 & 0.3 & 0.45 & 5.2 & 3.4 \\
\hline \hline
\end{tabular}

Table 2. Properties of the interface ${ }^{10}$

\begin{tabular}{ccccc}
\hline \hline $\mathrm{G}_{\text {Ic }}(\mathrm{N} / \mathrm{mm})$ & $\mathrm{G}_{\text {IIc }}(\mathrm{N} / \mathrm{mm})$ & $\mathrm{T}(\mathrm{MPa})$ & $\mathrm{S}(\mathrm{MPa})$ & $\eta$ \\
\hline 0.075 & 0.547 & 61 & 68 & 1.45 \\
\hline \hline
\end{tabular}

A complete analysis of the delamination growth in the tension specimen requires a high degree of complexity. For instance, Krueger ${ }^{10}$ developed highly detailed two-dimensional models using up to four elements per ply thickness. The approach taken here, on the other hand, is to determine if it is possible to predict the debond load of the specimen using decohesion elements in a much coarser threedimensional model. To keep the modeling difficulties low and the approach applicable to larger problems, the model that was developed uses only two brick elements through the thickness of the skin, and another two through the flange. The complete model consists of 1,002 three-dimensional 8-node C3D8I elements and 15,212 degrees of freedom. To prevent delamination from occurring at both ends of the flange simultaneously, model symmetry was reduced by 
modeling the tapered end of the flange with a refined mesh on one side and a coarser mesh on the other. This model does not contain any pre-existing delaminations.

Residual thermal effects are simulated by performing a thermal analysis step before the mechanical loads are applied. The same coefficients of thermal expansion $\left(\alpha_{1 I}=-2.4 \times 10^{-8} /{ }^{\circ} \mathrm{C}\right.$ and $\left.\alpha_{22}=3.7 \times 10^{-5} /{ }^{\circ} \mathrm{C}\right)$ are applied to the skin and the flange, and the temperature difference between the curing and room temperature is $\Delta \mathrm{T}=157^{\circ} \mathrm{C}$. The flange has more $90^{\circ}$ plies than $0^{\circ}$ plies and the skin is quasi-orthotropic, so it is expected that residual thermal stresses are present at their interface at room temperature.

\subsection{Tensile loading}

The specimen configuration corresponding to tensile loading is shown in Figure 5. The mechanism for debonding under axial load is primarily by shear lag.

Deformed plots of the finite element model immediately before and after flange separation are shown in Figure 5. It can be observed that only the refined end of the flange separates. A detailed analysis of the results indicated that the coarse end of the flange also softens, but that the separation of the flange at the refined end relieves the stresses at the coarse end. It is interesting to note that static tests exhibit debond of only one end while fatigue tests induce debonding at both ends ${ }^{10}$.

Note that the debond growth is not symmetric across the width: the debond initiates on the left corner of the flange, as shown in Figure 5, due to the unsymmetry introduced by the terminated plies at the flange tapered ends.

The load-extensometer measurement predictions are compared with the experimental data in Figure 6. The initiation of delamination is marked by the sharp breaks in the extensometer readings. Krueger et al. ${ }^{10}$ defined the damage initiation load as the load corresponding to the first load-drop before flange debonding. The numerical predictions and experimental results are shown in Table 3.

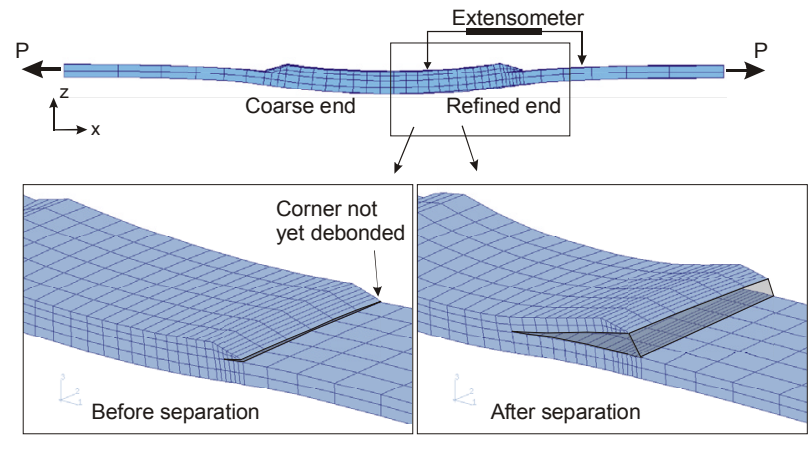

Figure 5. Deformed plots of skin/flange debond model.

It can be observed that good accuracy in the prediction of debond loads is obtained in the 2 cases investigated. Without thermal loads $\left(\Delta \mathrm{T}=0^{\circ} \mathrm{C}\right)$, the debond load is approximately equal to the maximum value obtained in the tests. The thermal loads $(\Delta \mathrm{T}=157$ ${ }^{\circ} \mathrm{C}$ ) cause an $8.5 \%$ reduction in the predicted debond load, which is now well within the range of the experimental results.The predicted stiffness of the specimen is also in good agreement with the experimental data until a relative displacement of approximately $0.06 \mathrm{~mm}$ is reached. For displacements higher than $0.06 \mathrm{~mm}$, the experimental data shows a stiffening effect. This effect is due to the fact that the relative displacement is measured using an extensometer placed between two points of the specimen. With increasing loads, the specimen's curvature also increases due to the higher bending moments, and the extensometer no longer measures the relative displacements in the global $\mathrm{x}$ direction shown in Figure 5.

Table 3. Experimental and numerical results (tension).

\begin{tabular}{|c|c|c|c|c|c|}
\hline & \multirow{2}{*}{$\begin{array}{c}\text { Exper. } \\
\text { Load }\end{array}$} & \multicolumn{4}{|c|}{ Analysis $\Delta \mathrm{T}=0^{\circ} \mathrm{C}$ Analysis $\Delta \mathrm{T}=157^{\circ} \mathrm{C}$} \\
\hline & & Load & Error & Load & Error \\
\hline $\begin{array}{c}\text { Damage } \\
\text { initiation } \\
\text { load }\end{array}$ & $20.9 \mathrm{kN}$ & NA & NA & NA & NA \\
\hline $\begin{array}{c}\text { Flange } \\
\text { debond } \\
\text { load }\end{array}$ & $22.7 \mathrm{kN}$ & $23.6 \mathrm{kN}$ & $4.0 \%$ & $21.6 \mathrm{kN}$ & $-4.8 \%$ \\
\hline
\end{tabular}




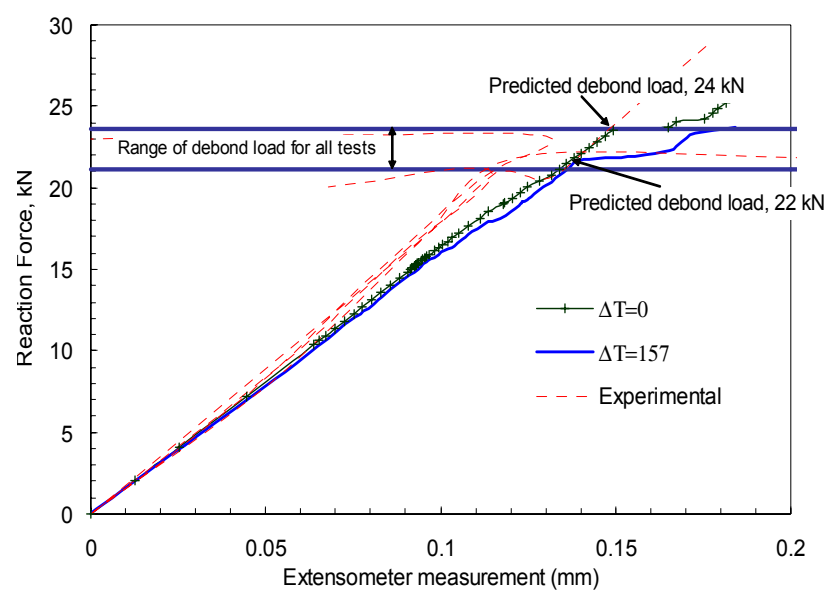

Figure 6. Predicted and experimental extensometer measurements.

\subsection{Three-point bending}

The three-point bending test specimen simulated is shown in Figure 4. The mechanism for the initiation of debonding under three-point bending is a combination of peel and interlaminar shear. Deformed plots of the finite element model simulating the three-point bending load case is shown in Figure 7. Debonding between the skin and the flange is considered to occur when a through the width crack is predicted. The predicted and experimental load displacement relation is shown in Figure 8. A comparison between the predicted and experimental damage initiation and debond loads is shown in Table 4.

Good accuracy in the prediction of both damage initiation and debond loads is obtained only when residual thermal stresses are taken into account. Without thermal stresses $\left(\Delta T=0^{\circ} \mathrm{C}\right)$, the debond load is overpredicted by $22.7 \%$. After debonding, the analysis including residual thermal stresses predicts a stable crack growth until a load of $572 \mathrm{~N}$ is attained. In contrast, the test specimens exhibited an unstable crack growth of approximately half of the span of the flange. In order to capture the unstable crack growth a more refined mesh, able to predict the condition of increase of energy release rate with increasing debond length at failure (neglecting R-curve effects), $\partial G / \partial a>0$, would be required. The stiffness of the skin-stiffener specimens is predicted accurately for the two conditions simulated.
Table 4 Experimental and numerical results (3-point bending).

\begin{tabular}{cccccc}
\hline \hline \multicolumn{5}{c}{ Exper. } & \multicolumn{4}{c}{ Analysis $\Delta \mathrm{T}=0{ }^{\circ} \mathrm{C}$} & \multicolumn{3}{c}{ Analysis $\Delta \mathrm{T}=157{ }^{\circ} \mathrm{C}$} \\
& Load & Load & Error & Load & Error \\
\hline $\begin{array}{c}\text { Damage } \\
\text { initiation } \\
\text { load }\end{array}$ & $428 \mathrm{~N}$ & $517 \mathrm{~N}$ & $19.4 \%$ & $419 \mathrm{~N}$ & $-2.1 \%$ \\
$\begin{array}{c}\text { Flange } \\
\text { debond } \\
\text { load }\end{array}$ & $463 \mathrm{~N}$ & $568 \mathrm{~N}$ & $22.7 \%$ & $514 \mathrm{~N}$ & $11.0 \%$ \\
\hline \hline
\end{tabular}

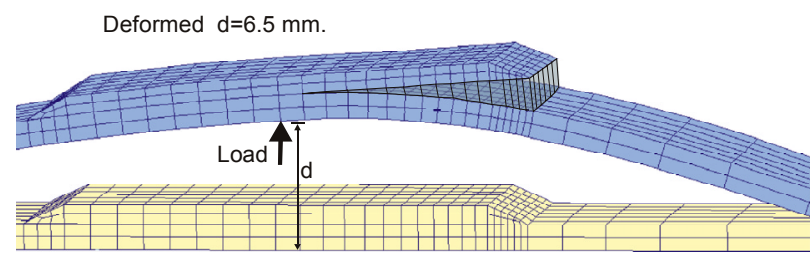

Undeformed

Figure 7. Deformed plots of skin/flange debond model (3-point bending).

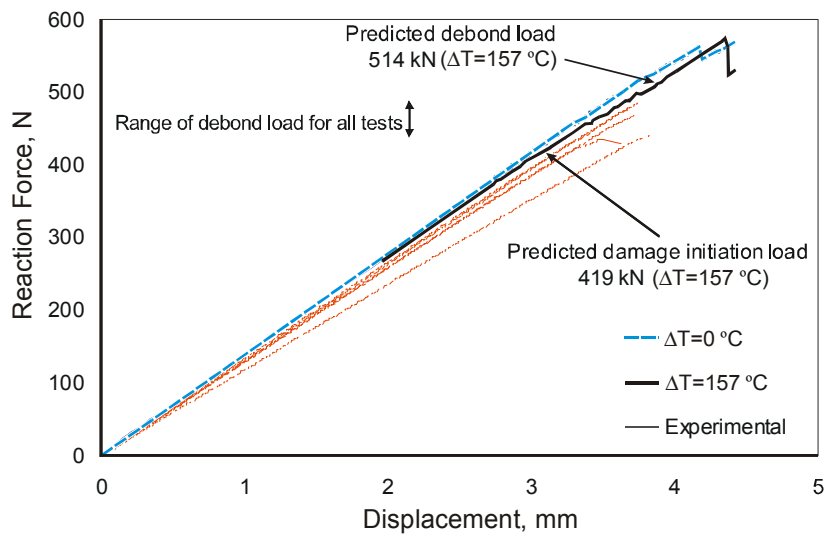

Figure 8. Predicted and experimental loaddisplacement relation.

\subsection{Effects of Bond Defects}

The manufacturing processes of laminated composite materials can lead to the existence of defects in the bonds. The debonds can be caused by air entrapped between plies or by inclusions in the prepreg. Furthermore, accidents such as tool drops, or other 
low-velocity impact loads, often lead to debonds that are difficult to detect. Under the previous circumstances, cracks will be present in the material before the application of the design loads. For damage tolerance considerations, it is therefore important to assess the structural behavior of composite materials in the presence of pre-existing debonds.

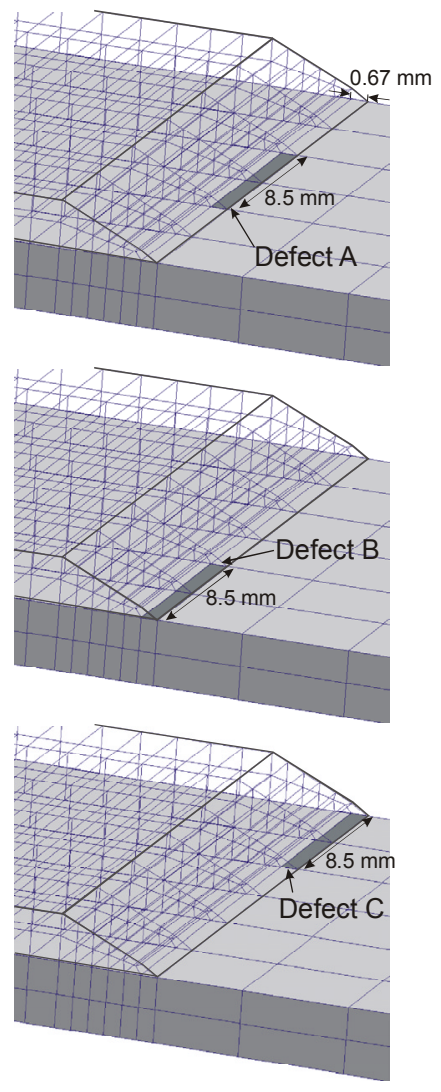

Figure 9. Location of defects.

The procedure previously proposed is used to simulate the response of tension-loaded skin-stiffener composite structures with bond defects. The three cases shown in Figure 9 are investigated. The three cases correspond to $8.5 \mathrm{~mm} \times 0.67 \mathrm{~mm}$ debonds located at different positions along the skin-flange interface. The defects are simulated by placing open decohesion elements at the corresponding positions. The analyses include the effects of residual thermal stresses.

The predicted load-displacement relations for an undamaged specimen and for the three cases under investigation is shown in Figure 10. The predicted debond loads and the difference between the debond loads for specimens with and without pre-existing defects are shown in Table 5.

Table 5. Predicted debond loads (tension).

\begin{tabular}{|c|c|c|c|c|}
\hline & \multicolumn{2}{|c|}{ No pre-crack Case A } & \multirow{2}{*}{$\begin{array}{c}\text { Case B } \\
17.3\end{array}$} & \multirow{2}{*}{$\frac{\text { Case C }}{19.1}$} \\
\hline $\begin{array}{l}\text { Flange debond } \\
\text { load }(\mathrm{kN})\end{array}$ & 21.6 & 20.7 & & \\
\hline Difference $(\%)$ & - & -4.2 & -19.9 & -11.6 \\
\hline
\end{tabular}

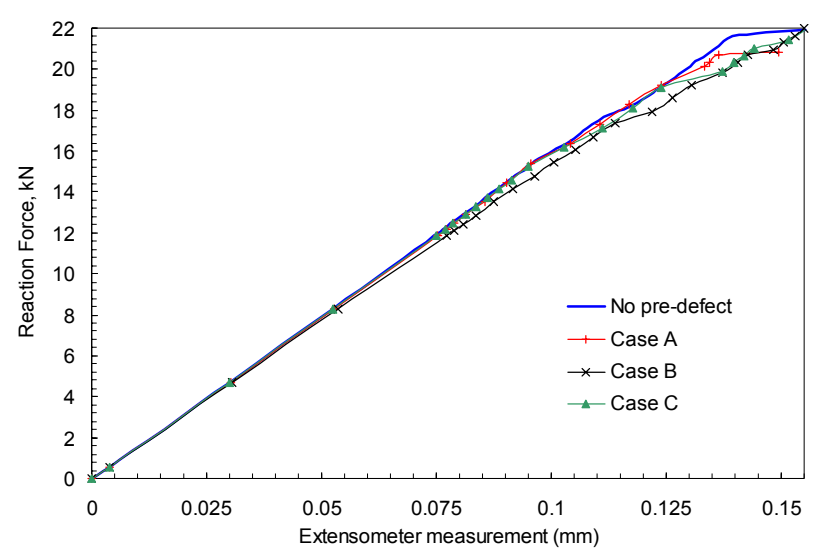

Figure 10. Predicted load-extensometer measurement for undamaged and damaged specimens under tension.

From the observation of Figure 10 and Table 5, it is clear that both the stiffness and the debond loads of the specimens are reduced by the pre-existence of bond defects. The effects of the pre-existing defects are more pronounced when the defects are located at the specimen's edges (cases B and C). The largest reduction of stiffness and debond load (19.9\%) corresponds to case $\mathrm{B}$, when the defect is placed at the position corresponding to the onset of debonding in the undamaged case.

\section{CONCLUDING REMARKS}

The debond strengths of skin/stiffener specimens loaded in tension and in three-point bending are investigated using a cohesive-zone model. The good agreement between the experimental and predicted location for crack initiation indicate that the proposed approach can capture the onset of damage in structures where the exact location of an initial crack may be difficult to determine a priori. 
For a skin-stiffener specimen under tension, good agreement between the experimental results and the numerical predictions is obtained. The stiffness of the specimen, the location of crack initiation, and debond loads are in good agreement with published experimental data. Neglecting residual thermal stresses leads to a $4.8 \%$ overprediction of the debond load.

For a skin/stiffener specimen under three-point bending, good agreement between the experimental and the numerical damage initiation and debond loads is obtained only when residual thermal stresses are taken into account in the analysis. This result indicates that the residual thermal stresses of the flange and the skin can cause a substantial reduction in the debond strength of the specimens when loaded in three-point bending. The simulation of the unstable crack growth following debonding under three-point bending requires a more refined mesh.

The effects of pre-existing bond defects in a specimen loaded in tension are investigated for a $8.46 \mathrm{~mm} \times 0.7 \mathrm{~mm}$ defect located at three different positions. In all cases a reduction of both stiffness and debond load are predicted. The importance of the location of the defect is reflected in the range of predicted reduction of debond load, from $4.2 \%$ up to $19.9 \%$. It is concluded that the approach proposed here can be used in the failure prediction of composite skinstiffener structural components when debonding is the leading failure mechanism.

\section{REFERENCES}

1. Camanho, P.P., and Matthews, F.L., "Delamination Onset Prediction in Mechanically Fastened Joints in Composite Laminates," Journal of Composite Materials, Vol. 33, No. 10, 1999, pp. 906-927.

2. Dávila, C.G., and Johnson, E.R., "Analysis of Delamination Initiation in Postbuckled DroppedPly Laminates," AIAA Journal, Vol. 31, No. 4, 1993, pp. 721-727.

3. Rybicki, E.F., and Kanninen, M.F., "A Finite Element Calculation of Stress Intensity Factors by a Modified Crack Closure Integral," Engineering Fracture Mechanics, Vol. 9, 1977, pp. 931-939.
4. Camanho, P.P., Dávila, C.G., and Ambur, D.R., "Numerical Simulation of Delamination Growth in Composite Materials," NASA-TP-2001211041, Hampton, VA, 2001.

5. ABAQUS V5.8 Users Manual, Hibbitt, Karlsson \& Sorensen, Inc., 1998.

6. Camanho, P.P. and Dávila, C.G., "Mixed-Mode Decohesion Elements for the Simulation of Delamination in Composite Materials," NASATM-2002-211737, Hampton VA, 2002.

7. Rice, J.R., "A Path Independent Integral and the Approximate Analysis of Strain Concentration by Notches and Cracks," Journal of Applied Mechanics, 1968, pp. 379-386.

8. Benzeggagh, M.L., and Kenane, M., "Measurement of Mixed-Mode Delamination Fracture Toughness of Unidirectional Glass/Epoxy Composites with Mixed-Mode Bending Apparatus," Composites Science and Technology, Vol. 56, No. 4, 1996, pp. 439-449.

9. Reeder, J.R., "An Evaluation of Mixed-Mode Delamination Failure Criteria," NASA-TM 104210, Hampton, VA, 1992.

10. Krueger, R., Cvitkovich, M.K., O'Brien, T.K., and Minguet, P.J., "Testing and Analysis of Composite Skin/Stringer Debonding under Multi-Axial Loading," J. Composite Materials, Vol. 34, No. 15, 2000, pp. 1263-1300. 